Equalita, Vol. 2 Issue 1, Juni 2020

Avaliable online at http://syekhnurjati.ac.id/jurnal/index.php/equalita/article/view/7062

Diterbitkan oleh Pusat Studi Gender dan Anak LP2M IAIN Syekh Nurjati Cirebon, Indonesia

\title{
PEMEROLEHAN FONOLOGI PADA ANAK YANG MENDERITA PALATOSIS
}

\author{
Leny Sri Wahyuni \\ IAIN Syekh Nurjati Cirebon
}

leny sriwahyuni@ymail.com

- Received:30 April 2020. •Accepted: 26 Mei 2020 •Published online: 30 Juni 2020

\begin{abstract}
Abstrak
Memasuki golden age period, kemampuan berbahasa seorang anak biasanya mengalami perkembangan yang signifikan. Namun, tidak semua anak dapat sempurna dalam memperoleh bahasanya, seperti yang dialami oleh DRS. DRS merupakan seorang anak perempuan berusia 3 tahun 1 bulan. Sejak lahir, DRS menderita palatosis yang mengakibatkan ia tidak mampu berbahasa seperti anak-anak seusianya. Ketidaksempurnaan artikulator yang dimiliki oleh DRS berimbas pada ketidakjelasan artikulasi fonem maupun kata yang dibunyikannya sehingga mengganggu proses pemerolehan fonologinya. Oleh karena itu, studi ini bertujuan untuk menginvestigasi fonem apa saja yang mengalami gangguan saat dilafalkan oleh penderita palatosis. Adapun, penelitian ini merupakan penelitian kualitatif dengan menggunakan metode studi kasus. Setelah dilakukan penelitian, DRS cenderung mengalami kesulitan dalam melafalkan bunyi-bunyi konsonan, terutama kesulitan saat melafalkan bunyi dental, alveolar, postaveolar, dan palatal, sebagai contoh ketidakjelasan pada pelafalan fonem $/ \mathrm{j} /$. Walaupun sudah dilakukan operasi penutupan celah pada langit-langit rongga mulutnya dan pemasangan obturatir, akan tetapi belum dapat sepenuhnya membantu DRS dalam memperoleh kemampuan fonologinya. Hal itu karena masih terdapat bunyi sengau di setiap pelafalan fonem-fonem konsonan yang dilafalkannya. Sementara itu, dalam pemerolehan bunyi-bunyi vokal, DRS tidak begitu mengalami kesulitan untuk melafalkannya, ia mampu melafalkan fonem /a/, /i/, /u/, /e/, dan juga /o/ dengan cukup baik.
\end{abstract}

Kata kunci: pemerolehan bahasa, golden age, fonologi, palatosis.

\begin{abstract}
Entering the golden age period, a child's language skill usually increase significant. However, not all children can acquire their language, as experienced by DRS. DRS is a girl aged 3 years and 1 month. When she was born, DRS has suffered from palatosis. Because of that, she can't speak like other children in her age. The imperfection of the articulator that is owned by DRS, it has an impact on the unclear articulation of the phonemes and the words they sound, which disturbs the process of obtaining the phonology. Therefore, this study aims to investigate which phonemes are interrupted when pronounced by sufferers of palatosis. Meanwhile, this research is a qualitative research by using the case study method. After doing the research, DRS tended to have difficulty pronouncing consonant sounds, especially difficulty pronouncing dental, alveolar, postaveolar, and palatal sounds, for example the unclear pronunciation of the phoneme / j / Although, surgery for cleft closure in the palate of his mouth and an obturate insertion had been performed, it was not yet able to fully assist DRS in obtaining its phonological abilities. This is because there are still nasal sounds in the pronunciation of the consonant phonemes that are pronounced. Meanwhile, in obtaining vowel sounds, DRS did not have much difficulty pronouncing them, she is able to pronounce the phonemes / a /, / i /, / u /, / e /, and also / o / quite well.
\end{abstract}

Keywords: language acquisition, golden age, phonology, palatosis 


\section{A. PENDAHULUAN}

Pada hakikatnya, setiap orangtua ingin memiliki anak yang sempurna lahir dan batinnya. Begitu pun dengan seorang anak, ia ingin terlahir tanpa kekurangan satu hal pun. Namun, tidak semua anak lahir dengan kondisi yang diharapkan. Beberapa anak terlahir tanpa kelengkapan organ sebagaimana mestinya. Hal tersebut membuat proses perkembangan kemampuannya pun menjadi terhambat.

Pada kasus yang peneliti temukan sebenarnya bukanlah kasus baru dalam dunia medis, namun untuk para linguis, ini merupakan kasus yang masih jarang diteliti. Ketidaksempurnaan organ wicara yang dialami oleh seorang anak perempuan telah menggugah ketertarikan peneliti untuk menelitinya. Menurut keterangan yang diberikan oleh ibunya, gadis kecil ini mengalami kebolongan langit-langit rongga mulut sejak lahir, yang mana dalam ilmu kedokteran kelainan itu disebut palatosis. Pujiastuti dan Hayati (2008) mengatakan bahwa celah atau bolong pada langitan merupakan kelainan yang sering terjadi pada congenital deformity setelah clubfoot deformity. Celah langitan (cleft palate) adalah kelainan karena terbukanya langit-langit rongga mulut. Penyebab celah langitan sampai saat ini belum diketahui dengan pasti, akan tetapi beberapa hipotesis mengemukakan bahwa kelainan ini bisa terjadi karena faktor genetik dan atau non genetik.

Penderita palatosis akan mengalami kesulitan dalam berbagai hal, seperti jalan nafas menjadi tersumbat, sulit untuk menelan makanan atau minuman (feeding problem) sehingga jika ibunya tidak berhati-hati saat menyuapinya maka dapat mengakibatkan si anak tersedak, bahkan bisa jadi makanan dan minumannya pun malah masuk ke paruparu atau hidung disebabkan tidak adanya katup penutup tenggorokan untuk mencegahnya. Selain itu, kelainan ini dapat pula menyebabkan berbagai masalah yang berhubungan dengan kemampuan bicara karena tidak sempurnanya alat artikulasi (artikulator) yang dimiliki oleh penderitanya. Oleh karena itu, penelitian ini memiliki tujuan untuk menginvestigasi fonem apa saja yang mengalami gangguan saat dilafalkan oleh penderita palatosis.

Teori pemerolehan bahasa (language acquisition) dipengaruhi oleh dua teori besar yang saling bertentangan, yaitu teori kaum behaviorisme dan teori kaum rasionalisme atau nativisme. Golongan kaum rasionalis menyakini bahwa "infant is born with certain innate (Lust, 2006)" sehingga melalui potensi bawaannya (inherent) seorang anak dapat menguasai kemampuan-kemampuan yang sudah menjadi kodratnya, terutama kemampuan untuk berbahasa. Pendapat kaum rasionalis itu didukung oleh Noam Chomsky. Chomsky (1999) mengatakan bahwa dalam otak manusia itu terdapat fakultas bahasa (language faculty) yang membantu manusia untuk dapat memperoleh dan menggunakan bahasa apapun yang menjadi bahasa pertamanya (first language). Dalam pemerolehan bahasa, anak akan dibantu oleh sebuah piranti yang disebut dengan Language Acquisition Device (LAD). LAD ini kemudian oleh Chomsky dikembangkan menjadi Universal Grammar (UG), yaitu Universal grammar is part of the genotype specifying one aspect of the initial state of the human mind and brain (Chomsky, 1999). Piranti penguasaan bahasa atau UG ini, meliputi: kemampuan membedakan bunyi 
bahasa dengan bahasa-bahasa lain, kemampuan menyusun bahasa menjadi sistem yang terstruktur, serta kemampuan mengetahui aturan yang mungkin atau tidak mungkin diterima dalam sistem bahasa pertamanya (Lust, 2006).

Berbeda dengan kaum rasionalisme, kaum behaviorisme menganggap bahwa seorang anak itu terlahir seperti tabula rasa (blank slate). Menurut Heidar (2012) blank slate diartikan sebagai kertas kosong yang menunjukkan bahwa anak lahir tanpa membawa kemampuan apapun, sehingga pengalaman anak-lah yang akan memberikan warna dan corak (input) pada kertas itu. Pelopor teori behaviorisme adalah Skinner. Konsep Skinnerian (Lust, 2006) ini, meliputi: (1) asosiasi Stimulus - Respon (S - R), yang mana anak akan mampu berbahas atau memproduksi bahasa (merespon) setelah ia mendapatkan stimulus sebagai inputnya; (2) pengkondisian (pembiasaan), melalui mekanisme ini anak dibiasakan untuk mendengar ujaran yang kemudian diasosiasikan dengan entitas atau kejadian yang terjadi, sehingga anak akan terbiasa untuk melafalkan bunyi fonem ataupun morfen yang telah dikondisikan untuk didengarnya; (3) peniruan (imitasi), imitasi terjadi ketika anak menirukan pola bahasa dari orang-orang disekitarnya; serta (4) penguatan, untuk memperoleh bahasa anak diberikan penguatan oleh orang disekelilingnya berupa respon positif.

Dukungan terhadap teori behaviorisme pun dilakukan oleh Michael Tomasello. Ia mengkritik Chomsky dan mengatakan bahwa seorang anak tidak akan mampu menggunakan bahasa begitu saja tanpa adanya proses seperti yang telah dikemukan oleh Skinner. Tomasello (2003) pun memberikan penguatan bahwa "children acquire language first and foremost by understanding how others use the language ", sehingga Tomasello menyakini bahwa bahasa bisa diperoleh karena bayi belajar meniru dari orang-orang disekitarnya terutama ibunya, ini yang disebut Tomasello sebagai Usagebased item by item imitative learning (Lust, 2006).

Selanjutnya, unit bunyi dibutuhkan oleh anak untuk dapat menghasilkan dan memperoleh sejumlah kemungkinan kata dan kalimat baru yang membantu anak agar mampu berkomunikasi, namun sebelum menghasilkan kata pertamanya seorang anak harus melakukan 'cracking the code' bahasa pertamanya. Lust (2006: 143) mmemmaparkan bahwa "the phonology of a language, is a necessary and primary step in cracking the code of the language surrounding the child", sehingga pemerolehan bahasa seorang anak akan dimulai dari pemerolehan fonologi, baru ke ranah lainnya, yakni pemerolehan sintaksis, semantik, dan pragmatik. Lust (2006) menambahkan bahwa perkembangan bahasa yang terjadi selama 12 bulan pertama bukan disandarkan pada sistem audiotori maupun pita suara, namun lebih kepada komputasi kognitif yang menghubungkan satu dengan yang lainnya serta pada phonological grammar dari bahasa yang diperoleh anak. Setelah itu, anak baru masuk ke fase perkembangan proses persepsi (speech perception) dan produksi ujaran (speech production).

Proses produksi ujaran berkembang sejalan dengan persepsinya. Seorang anak akan memproses sejumlah data yang diperolehnya melalui pengamatan panca indra, setelah itu akan diproses dalam otak yang diatur pada area wernicke, lalu pesan diteruskan melalui fasikulus arkuatum ke daerah broca untuk penguraian dan koordinasi verbalisasi pesan dari data yang diterima, kemudian signal itu akan melewati korteks motorik yang mengaktifkan otot-otot respirasi, fonasi, resonansi, dan artikulasi (Lust, 
2006). Lebih lanjut, dalam penelitian yang dilakukan oleh Kent dan Miolo tahun 1996 (Achmad \& Abdullah, 2012) dijelaskan bahwa sejak dalam kandungan anak sudah terekspos untuk mendengar dan memahami bahasa. Hal tersebut berdampak pada kemampuan persepsi seoranga anak akan lebih optimal dan jauh lebih cepat ketimbang kemampuan produksinya. Oleh karena itu, tidak aneh jika seoranga anak mampu memahami kata-kata atau kalimat yang belum mampu ia ucapkan, namun kata-kata atau kalimat tersebut sudah dapat dimengerti dengan baik oleh anak.

Adapun, fase seorang anak bisa berbahasa menurut Dardjowidjojo (2003) akan melewati fase-fase sebagai berikut: (1) Sekitar usia enam minggu pertama anak bayi akan melakukan dekutan (cooing). Pada fase ini, anak bayi mulai mengeluarkan bunyibunyi yang mirip dengan bunyi konsonan atau vokal, yang mana bayi akan memulai dan mengakhiri fonasinya dengan satu hembusan, sehingga bunyi-bunyi yang diproduksinya itu belum jelas terdengar dan belum dapat dipastikan bentuknya; (2) Ketika usia anak bayi mencapai enam bulan, ia akan mulai mengoceh (babbling). Pada fase ini, anak bayi melakukan ocehannya dengan mencampur huruf konsonan dengan vokal (KV). Biasanya konsonan pertama yang dibunyikan oleh anak adalah konsonan bilabial hambat /p/ dan /b/ serta bilabial nasal /m/ dengan kombinasi vokal /a/ sebagai vokal pertama yang biasa mengikutinya. Mengenai babbling ini, Lust (2006) mengungkapkan bahwa ada beberapa hipotesis yang mengungkapkan bahwa babbling dianggap hanya sekedar latihan artikulatori (vocal paly), hanya merefleksiskan kematangan secara biologis pada otak berdasarkan potensi bahasanya, serta hanya bentuk pemetaan properti-properti fonetik dan fonemik pada bahasa pertama yang diperoleh anak; (3) Pada saat anak bayi berusia 12 bulan, ia akan mengalami tahapan first word. Fase ini merupakan tahapan ketika anak bayi sudah mampu menghasilkan sebuah kata yang akan sangat membantunya untuk masuk ketahap produksi kalimat (holophrases) sederhana hingga kalimat kompleks.

Pada tahap perkembangan fonologi seorang anak, beberapa bunyi (fonem) akan diperoleh lebih awal, terutama bunyi-bunyi yang bersifat bilabial nasal. Roman Jakobson (dalam Lust, 2006) mengatakan bahwa pemerolehan bunyi berjalan selaras dengan kodrat bunyi itu sendiri, sehingga bunyi pertama yang keluar ketika anak mulai belajar fonologi adalah kontras antara konsonan dan vokal. Anak akan menguasai bunyi mengikuti urutan keuniversalan bunyi, hal itu yang membuat seorang anak akan mendahulukan pelafalan bunyi-bunyi yang lebih mudah. Maka, untuk lebih jelasnya perhatikan struktur bagan Hierarki Jakobson (Lust, 2006: 160). 
Gambar 1

Bagan

Hierarki

Jakobson

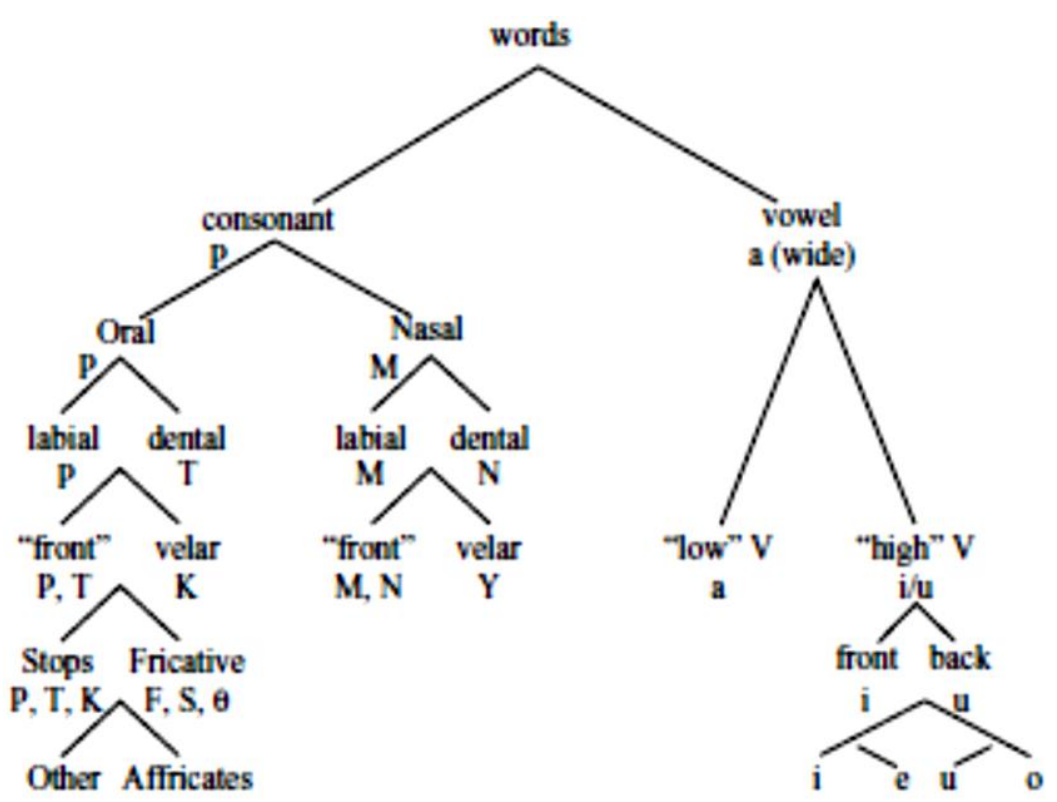

Selanjutnya, ihwal fonologi atau disebut juga sebagai bunyi bahasa. Menurut Achmad dan Abdullah (2013), fonologi merupakan bidang linguistik yang mempelajari, menganalisis, dan membicarakan runtutan bunyi-bunyi bahasa. Klasifikasi bunyi bahasa (classifying speech sounds) sendiri dikelompokan menjadi bunyi vocal dan konsonan. Menurut Muslich (2008), bunyi vokal (vokoid) merupakan bunyi yang dihasilkan dengan cara arus udara dari dalam tenggorokan tidak dihambat tetapi dibentuk. Adapun, proses pembentukannya dilakukan dengan cara 'bulat' seperti /u/ dan /o/, ada yang 'tinggi' seperti /i/ dan /u/, ada pula yang 'di depan' seperti /i/ dan /a/. Sementara, merujuk pada pendapat Roach (2001), bunyi konsonan (kontoid) adalah bunyi yang dihasilkan dengan menghambat aliran udara pada salah satu tempat artikulasi. Selain tempat artikulasi, bunyi konsonan ditentukan pula oleh bergetar tidaknya pita suara (voicing) dan cara arus udara dihambat oleh artikulator (manner of articulation). Adapun, salah satu alasan perlunya mempelajari fonologi adalah untuk mengetahui bagaimana seorang anak memperoleh kemampuan fonologinya sebagai bagian dari proses pemerolehan bahasa.

\section{B. METODOLOGI PENELITIAN}

Penelitian ini menggunakan pendekatan kualitatif. Seperti yang dikemukakan oleh Maxwell (dalam Alwasilah, 2008) pendekatan kualitatif memiliki keistimewaan tersendiri, yaitu dapat menginterpretasi fenomena-fenomena yang terjadi dalam ranah sosial secara lebih mendalam, mampu membedah pada pemahaman konteks tertentu, mampu mengidentifikasi fenomena dan pengaruh yang tidak terduga, dapat memunculkan teori berbasis data (grounded theory), menghasilkan pemahaman proses (dari pada produk) dari kejadian yang diamati, serta dapat menjelaskan hubungan sababiyah (causal explanation). Selanjutnya, metode penelitian yang digunakan adalah studi kasus (case study). Adapun, subjek penelitiannya ditentukan dengan menggunakan 
purposive sampling, yaitu seoranga anak perempuan berusia 3 tahun 1 bulan yang menderita palatosis dan telah melakukan operasi penutupan palatum. Sebagai bentuk dari etika penelitian, maka nama anak perempuan tersebut, peneliti inisialkan dengan sebutan DRS.

Terkait teknik pengumpulan data dilakukan dengan cara wawancara dan observasi. Teknik observasi dilakukan untuk mengetahui kemampuan anak dalam memperoleh fonologinya sehingga peneliti pun mengambil peran sebagai complete participant. Setelah itu, dilakukan wawancara kepada ibu dari anak yang diteliti. Wawancara dilakukan untuk memperoleh informasi rinci dan mendalam tentang hal yang dialami oleh DRS sehingga membantu mengkonfirmasi data yang diperoleh saat observasi. Adapun, ihwal Teknik analisis data dilakukan dengan beberapa tahapan, yaitu tahap reduksi data, tahap penyajian data, dan tahap verifikasi data.

\section{HASIL DAN PEMBAHASAN}

Merujuk pada informasi yang diperoleh dari ibunya, DRS sejak lahir mengalami masalah pada rongga mulutnya. Langit-langit rongga mulut DRS mengalami bolong. Dalam istilah medis, kelainan yang diderita DRS ini dinamakan palatosis atau sumbing palatum. Hal tersebut mengakibatkan DRS tidak bisa memperoleh ASI hingga pemerolehan bahasanya pun mengalami keterhambatan.

DRS mengalami kesulitan dalam berbicara karena adanya pengaruh dari ketidaksempurnaan rongga mulutnya. Sebelum dilakukan operasi cleft palate, setiap bunyi yang dilafalkan oleh DRS sangat tidak jelas dan sulit dimengerti, sehingga kedua orangtua DRS mencoba mengarahkan DRS agar memberikan signal atau tanda lain lewat ekspresi muka dan juga gesturnya untuk memudahkan DRS dalam mengkomunikasikan pesan yang ingin disampaikan ataupun hal yang ingin dilakukannya.

Selanjutnya, berdasarkan hasil wawancara yang telah dilakukan, DRS pun berhasil mendapatkan bantuan untuk menjalani operasi di salah satu Rumah Sakit Swasta di Bandung. operasi tersebut dilakukan dalam beberapa tahapan sehingga bisa membantu menutup celah langit-langit rongga mulutnya yang bolong dengan menggunakan alat yang bernama obturator. Menurut Pujiastuti \& Hayati (2008) obturator adalah suatu alat yang terbuat dari arilik keras dan lunak yang digunakan untuk menutup celah langitan. 


\section{Gambar 2 Obturator}

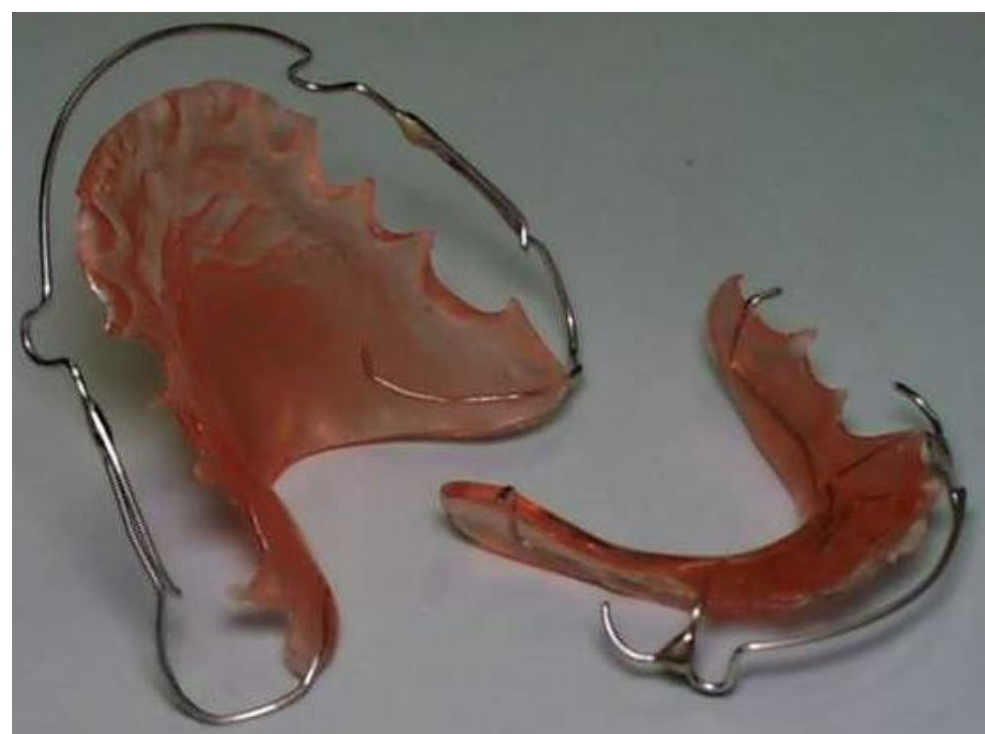

Sumber:https://www.google.com/imgres?imgurl=http://1.bp.blogspot.com/-

9S8ciDqkiRQ/UVA79fTMt7I/AAAAAAAAAvI/igQqzEsvg9w/s1600/retainertrad.jpg\&imgrefurl=http://ceritedoang.blogspot.com/2013 10 01 archive.html\&h=480\&w=640\&tbnid=ABgayIvGHsaO0M:\&docid=n4260PhEbvay7M\&ei=tY6IVpLiD8SHuASy LiQCg\&tbm=isch\&v $\underline{\text { ed=0ahUKEwjSkLWc04zKAhXEA44KHTI-DqIQMwguKBEwEQ\&biw=1366\&bih=631 }}$

Dengan menggunakan alat tersebut, DRS dapat mulai memfungsikan ronggga mulutnya untuk membantunya dalam hal menelan makanan, mempertahankan lebar lengkung maksila dan susunan gigi serta memperbaiki pertumbuhan langit-langit, serta memperbaiki fungsi bicara sehingga dapat menghindari adanya bunyi sengau atau desis. Fungsi lain dan alat ini adalah sebagai alat anti aspiration dan untuk mendapat bentuk palatum yang seperti normal agar lidah terbiasa pada posisi fisiologis. Alhasil setelah dilakukannya operasi palatum, produksi bunyi yang dihasilkan DRS mengalami perbaikan yang cukup signifikan, dari awal tuturan yang sangat tidak jelas fonasinya sekarang sedikit demi sedikit menjadi lebih jelas secara artikulasi dan lebih mudah dimengerti, walaupun belum bisa setepat artikuasi anak-anak normal seusianya.

Gambar 3 Rongga Mulut DRS sebelum operasi

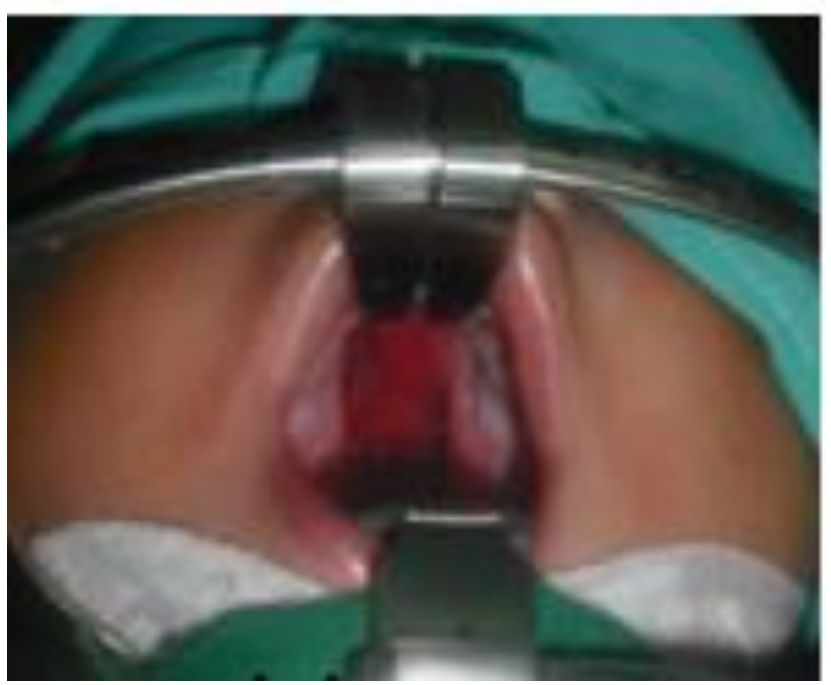


Gambar 4 Rongga Mulut DRS sesudah operasi

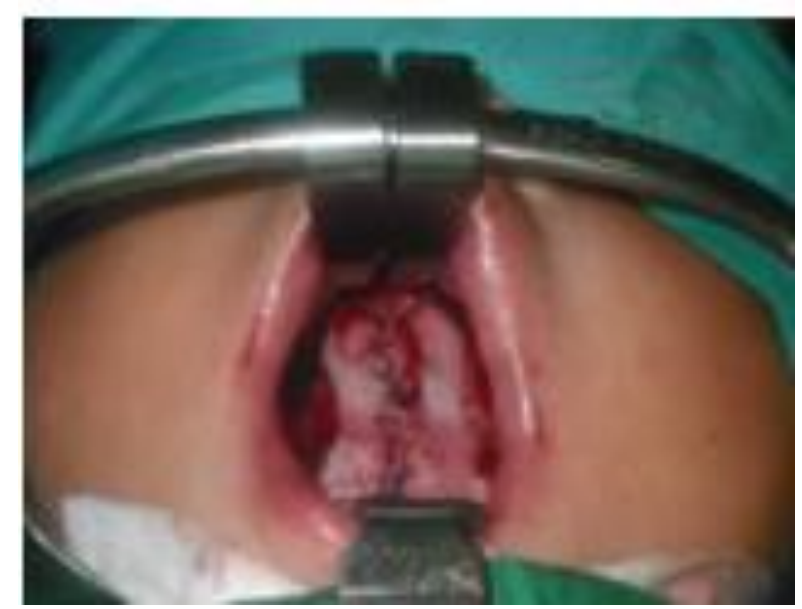

Adapun merujuk pada hasil observasi dan juga wawancara maka tahapan pemerolehan bahasa DRS hampir sama dengan anak-anak yang terlahir normal lainnya, yaitu melalui tahapan crying, ketika lahir DRS mengeluarkan bunyi tangis yang sama seperti anak pada umumnya (menangis secara normal), sehingga orangtua bahkan bidan yang membantu persalinan pun tidak mengetahui bahwa DRS mengalami kebolongan pada langit-langit rongga mulutnya. Oleh karena itu, palatosis yang dialami DRS baru diketahui beberapa minggu berikutnya ketika DRS mengalami kesulitan dalam menyusu. Pasca air susu sang bunda tidak bisa disedot oleh DRS hingga berdampak pada merosotnya berat badan DRS, lalu kedua orangtua DRS pun melakukan konsultasi ke dokter spesialis anak, dan setelah dilakukan pemeriksaan ternyata langit-langit rongga mulut DRS bolong. Mengetahui hal itu, orangtua DRS mencari informasi untuk menangani kelainan DRS, yang pada akhirnya dokter menyarankan untuk melakukan operasi palatum.

Dengan kondisi langitan yang bolong tidak membuat DRS melewati tahap pemerolehan bahasanya. Hal tersebut ditunjukkan dengan dilaluinya fase cooing. Pada tahap ini, DRS tetap bisa melakukan proses dekut dengan mengeluarkan bunyi dari rongga mulutnya. Namun, gejala keterlambatan berbicara DRS mulai terlihat pada tahap Babbling, First Word dan Holophrastic Stage. DRS semakin menunjukan ketidakberdayaannya dalam membunyikan bunyi-bunyi yang seharusnya sudah semakin jelas seiring perkembangan usianya. Keterlambatan berbahasa yang dialami DRS dan ketidakjelasan bunyi yang dihasilkannya terjadi karena pengaruh langit-langit rongga mulut yang bolong sehingga semua bunyi yang dihasilkan terdengar sengau.

Adapun, berdasarkan hasil observasi diketahui bahwa kemampuan DRS dalam pemerolehan bunyi-bunyi vokal bisa dikatakan lebih baik dibanding kemampuannya dalam memperoleh bunyi-bunyi konsonan. Hal tersebut karena fonem-fonem vokal /a/, /i/, /u/, /e/, dan juga /o/ lebih mudah dibunyikan ketimbang fonem-fonem konsonan /b/, /c/, /d/, /f/, dan seterusnya. hal tersebut sebagaimana yang dikemukan oleh Roach (2001) 
bahwa huruf-huruf vokal dihasilkan dengan membentuk udara, berbeda dengan huruf konsonan yang dihasilkan dengan menghambat aliran udara di daerah artikulasi tertentu sehingga membuat bunyi vokal lebih mudah dihasilkan. Daerah artikulasi sendiri merupakan titik pertemuan antara artikulator aktif (bergerak) misalnya lidah dengan artikulator pasif (diam) seperti langit-langit mulut, yang mana saluran udara akan dihalangi (dihambat) oleh artikulator tersebut untuk menghasilkan bunyi konsonan. Oleh karena artikulator pasif yang dimiliki DRS mengalami kelainan, maka secara otomatis pasti akan mengganggu kualitas bunyi yang dihasilkan dan membuatnya sulit membunyikan fonem-fonem kontoid.

Berdasarkan temuan lainnya, ternyata keuniversalan hierarki Jakobson pun tidak berlaku untuk DRS, itu disebabkan DRS adalah anak yang istimewa. Dalam hierarki Jakobson ketika seorang anak mampu membunyikan fonem /k/, ia pasti sudah dapat membunyikan fonem /t/. Namun, hal yang terjadi pada DRS, ia tidak dapat membunyikan fonem / $\mathrm{t}$ / padahal untuk fonem /k/, contohnya seperti penggunaan pada kata 'kuda', ia sudah mampu membunyikannya dengan baik.

Selanjutnya, kesulitan DRS dalam membunyikan fonem-fonem konsonan terjadi pada titik artikulasi dental, alveolar, postaveolar, dan palatal, terutama untuk bunyibunyi yang diartikulasikan dengan cara plosive (konsonan letup), fricative (bunyi fonem kosonan yang dilakukan secara mendesah), africative (bunyi konsonan kompleks yang dimulai secara plosive dan berakhir sebagai fricative), dan lateral (samping). Bunyi fonem /d/ dan /t/ merupakan bunyi alveolar plosive yang dihasilkan dengan cara menghambat aliran udara, yang dilakukan oleh artikulator aktif, yakni lidah pada gusi sebagai artikulator pasifnya. Penghambatan udara tersebut sulit dilakukan oleh DRS karena letak gusi memiliki kedekatan jarak dengan langit-langit rongga mulut, yang mana langit-langit rongga mulut DRS bolong, sehingga mengakibatkan DRS tidak bisa melafalkan fonem tersebut. Sebagai contoh, DRS tidak mampu menyebut ibunya dengan sebutan 'bunda', sehingga bunyi kata yan dihasilkan menjadi 'buma'. Hal itu terjadi karena fonem /d/ tidak bisa dibunyikan oleh DRS sebab artikulator pasifnya tidak sempurna.

Bunyi alveolar fricative, yaitu fonem /s/ dan /z/, tidak bisa dibunyikan pula oleh DRS. Hal tersebut karena aliran udara dipaksa keluar melalui celah sempit antara alveopalatal dengan badan lidah. sehubungan dengan terjadinya lubang pada langitlangit rongga mulut DRS mengakibatkan ia tidak bisa membunyikan Bunyi alveolar fricative. Oleh sebab itu, kata 'awas' akan dibunyikan oleh DRS menjadi kata 'awah'. Dengan demikian, untuk fonem /s/ pada kata 'awas' berubah menjadi fonem / $\mathrm{h} /$ yang berbentuk glotal fricative, itu berakibat pada perubahan bunyi 'awas' menjadi 'awah'.

Bunyi palatal pun, yaitu pada fonem /j/, tidak mampu dibunyikan oleh DRS. hal tersebut dibuktikan pada kata 'janji' berubah bunyinya menjadi 'nyanyi' ketika dilafalkan oleh DRS. Begitupun untuk bunyi lateral pada fonem /l/, DRS cenderung membunyikannya menjadi bunyi /y/. Sebagai contoh kasus, yaitu ketika DRS ingin memanggil sodara sepupunya dengan sebutan 'A Ilam' bunyi yang dihasilkan malah menjadi 'A Iyam'. Oleh karena itu, bunyi konsonan yang 


\section{SIMPULAN}

Ketidaksempurnaan rongga mulut yang dimiliki DRS akibat langit-langitnya bolong menyebabkan terjadinya perubahan bahkan perbedaan kualitas bunyi yang dihasilkan. Walaupun DRS sudah menjalani operasi, namun masih ada fonem-fonem yang belum bisa dibunyikannya dengan baik, sehingga diperlukan terapi wicara untuk memperbaiki kualitas dari artikulasinya. Fonem-fonem yang dimaksud adalah bunyi-bunyi konsonan pada titik artikulasi dental, alveolar, postalveolar dan palatal. Hal tersebut sebagaimana terjadi pada pelafalan fonem /s/, /j/, /l/ yang tidak bisa dibunyikan dengan tepat bahkan untuk fonem / $\mathrm{t} / \mathrm{dan} / \mathrm{d} /$ cenderung menghilang. Adapun, untuk pelafalan bunyibunyi vokal, DRS ternyata mampu melakukannya dengan baik.

\section{DAFTAR PUSTAKA}

Alwasilah, A. Chaedar. 2008. Pokoknya Kualitatif. Bandung: Dunia Pustaka Jaya.

Achmad., \& Abdulah, Alex. 2012. Lingustik Umum. Jakarta: Erlangga.

Chomsky, Noam. 1999. On the Nature, Use, and Acquisition of Language. In W. C. Ritchie and T. K. Bhatia (eds.), Handbook of Child Language Acquisition. San Diego, CA: Academic Press.

Dardjowidjojo, Sunaryo. 2003. Psikolinguistik. Jakarta: Yayasan Obor Indonesia.

Heidar, Davood Mashhadi. 2012. First Language Acquisition: Psychological Considerations and Epistemology. Theory and Practice in Language Studies, Vol. 2, No. 2, hal. 411-416. Doi:10.4304/tpls.2.2.411-416.

Lust, Barbara. 2006. Child Language: Acquisition and Growth. New York: Cambridge University Press.

Muslich, Masnur. 2011. Fonologi Bahasa Indonesia. Edisi 1 cetakan ke- 4. Jakarta: Bumi Aksara.

Pujiastuti, Nurul., \& Hayati S. Retno. 2008. Perawatan Celah Bibir dan Langitan pada Anak Usia 4 Tahun. Indonesian Journal of Dentistry; Vol. 15, No. 3, hal. 232-238.

Roach, Peter. 2001. Phonetics. New York: Oxford University Press.

Tomasello, Michael. 2003. Constructing a Language: A Usage-Based Theory of Language Acquisition. Cambridge: Harvard University Press.

https://www.google.com/imgres?imgurl=http://1.bp.blogspot.com/-

9S8ciDqkiRQ/UVA79fTMt7I/AAAAAAAAAvI/igQqzEsvg9w/s1600/retainertrad.jpg\&im grefurl=http://ceritedoang.blogspot.com/2013 1001 archive.html\&h=480\&w=640\&tb nid=ABgayIvGHsa00M:\&docid=n4260PhEbvay7M\&ei=tY6IVpLiD8SHuASy LiQCg\&tbm= isch\&ved=0ahUKEwjSkLWc04zKAhXEA44KHTI-

DqIQMwguKBEwEQ\&biw=1366\&bih=631. (Diakses pada hari Minggu tanggal 23 Agustus 2020, pukul 10.30 WIB) 